\title{
How Are We Doing? An Examination of Gender Representation in Industrial and Organizational (I-O) Psychology
}

\author{
Danielle M. Gardner, Ann Marie Ryan, and Megan Snoeyink \\ Michigan State University
}

\begin{abstract}
There has been an explosion of within-profession studies examining standings on gender representation in advancement, publication patterns, and conference presentations. However, industrial and organizational (I-O) psychology has yet to take such an introspective look and fully join these conversations. This manuscript aims to initiate and encourage such discussion. Through a brief review of relevant background information and the collection and analysis of recent archival data, we seek to examine where we have been with regard to gender representation, where we currently stand, and what steps are needed moving forward. We aim to stimulate continued examinations on this topic while recommending appropriate action items relevant to achieving equity in representation in our field.
\end{abstract}

Keywords: gender representation, gender equity, female advancement, recognition

Despite women now comprising the majority of college students and bachelor degree recipients (Goldin, Katz, \& Kuziemko, 2006), men continue to retain majority representation in many fields of academia (Council of Canadian Academies, 2012) and the business world (Catalyst, 2017; Faccio, Marchica, \& Mura, 2016). As the gender composition of those entering professions changes, special attention has been drawn to any gender disparities in advancement or outcomes in the workplace. Although topics such as rates of advancement, the glass ceiling, and the like have long been a target of workplace research (e.g., Morrison \& von Glinow, 1990), there has been an explosion of within-profession studies in the sciences examining gender differences in advancement (e.g., computer science, Way, Larremore, \& Clauset,

Danielle M. Gardner, Michigan State University; Ann Marie Ryan, Michigan State University; Megan Snoeyink, Michigan State University.

We wish to thank all those who provided program or personal information to assist us with this article, including faculty at I-O programs, SIOP Fellows, and the SIOP Office.

Correspondence concerning this article should be addressed to Danielle M. Gardner, Michigan State University, Department of Psychology, 316 Physics Road \#262, East Lansing, MI 48824. E-mail: gardn333@msu.edu 
2016; medicine, Economou, 2014), publication patterns (e.g., in mathematics, Mihaljevic-Brandt, Santamaria, \& Tullney, 2016; across science, technology, engineering, and math (STEM) fields, Zeng et al., 2016), and conference presentations (e.g., anthropology, Isbell, Young, \& Harcourt, 2012).

Although a number of disciplines have introspectively evaluated their own standings with regard to gender representation, industrial and organizational (I-O) psychology has yet to fully join these discussions. Consequently, this article seeks to initiate such conversation. Our goal is to provide some basic gender representation information in relation to our field and to encourage subsequent commentary, research, and actionable next steps. Such an examination is important for many reasons, but we note in particular three that prompted our attention. First, as researchers who investigate topics related to discrimination, we are acutely aware of both the prevalence of bias and barriers in workplaces as well as the misattributions to discrimination that can be made. Our aim is to spur people in our field to gather the data needed to take an objective look at these topics rather than to conclude inequities do or do not exist based on limited and often ambiguous information. Second, relative silence on a topic may signal there is nothing to talk about, but it also may signal lack of interest, inability to voice, and/or unwillingness to address a topic. Although there are occasional conference sessions targeted toward women's advancement within our profession, and there is a very recently formed women's network within the Society for Industrial and Organizational Psychology (SIOP), fostering greater conversation will likely be a positive outcome for our field. Third, as our professional society strives to put best practice to work in its operations (e.g., selection of staff, member surveying), reflecting on best practices put forth from gender equity research and whether, how, and when they might be applied to our practice, teaching, and research endeavors is in keeping with a broader desire to practice what we preach.

After providing a very brief historical synopsis of research on gender in the I-O profession and a quick snapshot of current gender composition of the field, we explore gender representation in a number of areas typically discussed in evaluating gender equity (e.g., salary, advancement, recognition), as well as in work outcomes more specific to scientific fields (e.g., publications, presentations, editorships) with the aim of applauding evidence of equity in our field, pointing out any potential gaps, and stimulating discussion and research. We acknowledge upfront that our review is quite cursory and our analyses merely descriptive; strong inferences regarding any potential gender inequity and its causes require richer data and more sophisticated examination. However, we feel that this overview can provide some useful information to start such examination, point to where energies might best be focused, and create an appropriate agenda for the profession in this regard. 


\section{Relevant Background Information \\ Briefest Historical Lens}

In her review of American female pioneers of I-O psychology, Koppes (1997) noted that "compared with other sciences, women constituted a larger proportion of psychologists during the formative years" (p. 500). Despite that, I-O had the lowest proportion of women in the applied areas. Koppes also pointed out that there was solid evidence of women's early scholarly contributions, as DeMeuse's (1987) review of Journal of Applied Psychology (JAP) articles from 1917-1919 showed that $16.7 \%$ of senior authors were women, and between 1920 and 1929 24.6\% of senior authors were female. Fast forwarding to the end of the century, one also finds some examinations of authorship and gender. In 2000, Ones and Viswesvaran found that women published less than men in two leading journals in the field (JAP and Personnel Psychology) in the 1990s (standardized mean difference in number of papers was .28 favoring men).

In 2004, Judge, Kammeyer-Mueller, and Bretz published a paper on I-O academic psychologists' career outcomes that indicated that women had significantly lower levels of success (extrinsic success was a composite of rank, salary, citation rates, prestige of current job, fellowships, and presence on editorial boards; intrinsic success was defined as career satisfaction). They noted that although variables in their model (e.g., career publications) explained to some extent why the gender differences in career success occurred, they did not account for all the factors that might explain gender differences. Judge et al. suggested that there may be an accumulated advantage for gender, such that men's better initial success (i.e., more likely to obtain better initial jobs, more likely to work with productive chairs) leads to an advantage that accumulates so that the gender effect becomes stronger over the course of a career. Although they advocated for further research on this possibility, little attention to gender has occurred since then. Further, the focus of attention has primarily been on publications and academic success rather than a broader view that would include women's success in the practice domain.

\section{Current Representation}

Data obtained from the SIOP Administrative Office (personal communication, December 21, 2016) indicate that of those SIOP members who indicated gender (only $60 \%$ provided this information), $52.0 \%$ were female. The membership data provided by SIOP also indicates some small differences in gender balance across primary employment settings, with $42.6 \%$ of academics who provided information indicating they are female, $49.2 \%$ of those in private sector female, and $53.7 \%$ of those in government settings female. Similarly, Table 1 outlines the gender breakdown of individuals in various fields based on the 2011 SIOP Membership Survey (25\% response rate; 800 
Table 1. Gender Breakdown of Major Employment Settings for Those in the I-O Psychology Field Based on the 2011 SIOP Membership Survey

\begin{tabular}{lcc}
\hline \hline Setting & Male & Female \\
\hline Consulting firm/private practice & $56 \%$ & $44 \%$ \\
University/private college & $56 \%$ & $44 \%$ \\
Private sector & $52 \%$ & $48 \%$ \\
Nonprofit research organization & $28 \%$ & $72 \%$ \\
Public sector organization & $44 \%$ & $56 \%$ \\
Other academic institution & $38 \%$ & $63 \%$ \\
Retired & $86 \%$ & $14 \%$ \\
Other & $52 \%$ & $48 \%$ \\
\hline \hline
\end{tabular}

female, 797 male). From examining the table, we notice a relative equal split across the most common work settings (consulting firm/private practice and university/private college), with more women in the less "traditional" settings of nonprofit and other academic institutions.

In terms of whether the composition of the field is changing, $56.8 \%$ of student members who provided gender information were female. To gain a sense of the gender breakdown of recent I-O graduates entering the field, we contacted faculty representatives at each of the $40 \mathrm{I}-\mathrm{O} \mathrm{PhD}$ programs identified by Beiler, Zimmerman, Doerr, and Clark (2014), requesting the number of male and female graduates between 2012 and 2016. Of these 40 programs, we received gender information for 451 graduates of 29 programs. The collective gender breakdown tended to be female skewed, in that 273 $(60.5 \%)$ of graduates were women and $178(39.5 \%)$ were men.

Thus, overall the field of I-O psychology appears relatively gender balanced in membership according to SIOP membership statistics and recent member surveys; however, there is also evidence that the field is tilting female based on demographics of recent graduates. We encourage readers to note these baseline estimates of gender balance in numbers within the field when considering the topics that follow, including salary, advancement, recognition, conference presentations, and journal publications.

\section{Examination of Gender Representation in I-O Psychology Income}

There is a sizeable body of research on gender equity in pay, including studies that focus in on particular sectors and levels (e.g., in academia, Lee \& Won, 2014; in executive level jobs, Burress \& Zucca, 2004). To address gender equity in income within our profession, we look at available data, pose areas that might be fruitful to examine, and suggest next steps. 
How are we doing? The most recent SIOP salary survey (http://www. siop.org/tip/Jan17/Report.pdf) provides detailed gender comparisons of salary, noting that the 2015 median income for men in I-O was $\$ 116,779$ (mean of $\$ 138,873$ ) and for women was $\$ 104,750$ (mean of $\$ 117,985$ ), with both mean and median indicating significant differences. The report notes that the salary gap in I-O has been narrowing over time, with the median income for women in I-O rising at a higher rate than men's since 1982, and that the female-to-male ratio in income in I-O (89.7\%) is higher than the typical range (80-83\%, U.S. Bureau of Labor Statistics, 2015). Although the report notes this is favorable information, it also notes that the gender wage gap in I-O is persistent and will not be eradicated at current growth rates for at least another decade.

What do we need to explore? Quality gender equity studies do not simply look at income differences but consider all the various human capital and market factors that relate to pay, any number of which might demonstrate gender differences (e.g., hours worked, O’Neill \& O'Reilly, 2010). To really understand any gender pay gap in our field, we need to assess and account for such factors, but such data are not readily available. There are other topics related to gender and pay that we might consider as well. For example, considerable research exists on gender differences in pay negotiation (e.g., Leibbrandt \& List, 2015): To what extent do women and men approach pay negotiation differently in our field? In addition to the helpful information in the salary survey, how might SIOP provide resources for those seeking to negotiate raises and better starting salaries? Research also has focused on gender differences in pay expectations (e.g., Hogue, DuBois, Fox-Cardamone, 2010; Jackson, Gardner, \& Sullivan, 1992): What are the expectations of new graduates in I-O? Other research points to task segregation within occupations (e.g., more female than male doctors, nurses, and physicians assistants in certain sub-specialties). To what extent is there differential gender representation within I-O in sub areas of specialization (e.g., less women in selection and psychometrics), and how might that relate to salary? With regard to the growth rates of salary within I-O, a considerable body of research suggests that as the proportion of females in an occupation increases, there is a net negative effect on pay-a phenomenon often explained by devaluation theory that suggests women's work is culturally devalued (see Magnusson, 2009, for a review). The SIOP salary survey shows salary growth from 1982 on, although examining devaluation theory would necessitate examining gender composition over time along with relative growth rates in other professions not experiencing changes in gender composition (or controlling for those changes).

What are needed next steps? In order to be able to do an adequate study of pay equity in our field, we need sufficient individual motivation to 
provide accurate information on salary and human capital factors to interested researchers, and sufficient profession-wide motivation to set aside resources to conduct a thorough study. Given how much work individuals on the SIOP Income and Employment Survey Team put into that effort to get us this far in terms of information, overcoming this information gap appears to be a significant challenge.

\section{Advancement}

Considerable research has focused on advancement rates of women relative to male counterparts in many disciplines (e.g., in economics, McDowell, Singell, \& Ziliak, 2001; vision sciences, Cooper \& Radonjic, 2016). Within academic settings, comparisons of gender representation by rank are common, with studies typically showing that women comprise lower proportions of higher ranks (e.g., $42.6 \%$ of assistant professors and $21.7 \%$ of full professors in Canada, across humanities, life sciences, and physical sciences, Council of Canadian Academies, 2012; 15\% of full professors in computer science, Way et al., 2016). This is often described as a "leaky pipeline," where comparisons of proportions at entry to advance ranks differ [e.g., while $47 \%$ of medical school graduates in 2011 were female, Economou (2014) found that women only occupied $37 \%$ of full time faculty and $13 \%$ of full professor positions]. Looking specifically to psychology, Geraci, Balsis, and Busch (2015) found that $35 \%$ of full professors were women despite the majority of individuals in the field being female (i.e., a female to male ratio of 2.1:1, APA Center for Workforce Studies, 2015). Outside of academic settings, there is also substantial research on gender and advancement, with particular attention to the "glass ceiling" or lack of advancement beyond a certain point (e.g., Cook \& Glass, 2014; Russo \& Hassink, 2012).

How are we doing? Descriptive data on job level in our field is more readily available on the academic side. To gain a glimpse, we identified the top 40 industrial-organizational $\mathrm{PhD}$ programs ranked by overall faculty productivity (Beiler et al., 2014), and using each program's website information, we recorded faculty members' gender and rank. We specifically looked at tenure-track/tenured faculty members and did not include teaching faculty, visiting scholars, or emeritus faculty within our data set. One school did not provide information on faculty rank, so it was not included in our analyses. The final data set included 220 faculty members from $39 \mathrm{I}-\mathrm{O} \mathrm{PhD}$ programs, of which 131 (59.5\%) were male and 89 (40.5\%) were female. Significant differences existed between male and female faculty members in rank, such that men tended to hold higher ranked positions $(M=2.41, S D=0.73)$ than women $(M=2.10, S D=0.84), F(1,219)=8.48, M S E=0.61, p=$ .004 . That is, women are holding more assistant faculty positions than men in these programs, and men hold more associate and full professorships than 
women. Note that this analysis does not speak at all to promotion rates, time to advance, or criteria used in evaluating candidates but simply reflects representation at current job levels. Finally, we found no significant differences in gender representation by program ranking $F(1,219)=0.64, M S E=139.32$, $p=.425$.

What do we need to explore? On the practice side, there are not readily available data to draw upon to even begin to consider questions of advancement in I-O. Addressing advancement in practice would require methodologies employed in studying the issue more broadly (e.g., Konrad \& Cannings, 1997; Lyness \& Thompson, 2000; Tharenou, 1999) such as considering the nature of work experiences and other human capital factors. However, we would note that such efforts are worth pursuing and would encourage SIOP to include gender as a variable in future practitioner surveys so as to shed light upon issues of gender and advancement in that context. Further, our analysis describing rank on the academic side speaks only to current composition of faculty ranks in a subset of I-O programs (not to faculty in business schools, masters programs, or the full range of $\mathrm{PhD}$ and $\mathrm{PsyD}$ programs, or to those teaching I-O at undergraduate institutions); it does not speak to gender equity in representation (as we do not have data on how many women enter the faculty pipeline in these types of programs), nor does it address issues of rates of advancement or factors considered in advancement decisions. Other analyses that would be helpful would involve tracking all entrants to our field over time: Of those who graduate from I-O programs, how many stay in the field? Are there gender differences in retention rates such that we have a leaky pipeline, or is this not a problem? At a broader level, we know there are sex differences in the likelihood that $\mathrm{PhDs}$ will apply for assistant professor positions in a number of fields, especially at research-intensive universities (Ceci, Ginther, Kahn, \& Williams, 2014), but we also know that women who apply are often interviewed and hired at greater rates than men (Valla \& Ceci, 2014). As a profession, are we tracking individuals' career experiences through the transition from $\mathrm{PhD}$ to placement? For example, what jobs are individuals seeking? Are they obtaining them? What data can we bring to bear on the practice side, where advancement rates post- $\mathrm{PhD}$ may be more difficult to quantify? Further, some researchers (Gino, Wilmuth, \& Brooks, 2015) have argued that women view high-level positions as less desirable and prioritize other life goals (see also Litzky \& Greenhaus, 2007). Others have noted gender bias in perceptions of derailment potential (Bono et al., 2016): How is the future potential of early career individuals in our field viewed? What do we know about the views of women in I-O regarding career expectations?

Another area that has been examined in a number of professions is whether there are differences in training or in treatment of entrants to the 
field. For example, Sheltzer and Smith (2014) showed that in the life sciences, male faculty, particularly those who might be considered of elite status, train fewer female graduate students and post-docs relative to their representation. Within I-O, we might wish to invest in better tracking of the recruitment, retention, and training of those entering our field. This might include consideration of more indirect interpersonal discrimination, as indicated by Milkman, Akinola, and Chugh (2015), who showed, across a number of fields, that emails from prospective graduate students with male names are responded to more frequently than those written with female names.

An additional area that might deserve further research attention on both the academic and practitioner side is whether there are any gender differences in professional networks. There are a number of studies that have examined men's and women's networks inside organizations (in terms of access and advancement; e.g., Brass, 1985; Ibarra, 1992), in terms of finding jobs and/or obtaining contract work (Lutter, 2015; Merluzzi \& Sterling, 2017), and specifically in terms of academic success (e.g., Brink \& Benschop, 2014; Parker \& Welch, 2013). Within I-O psychology, we might gather data to consider the extent of homophily in networks, and also research the relation of gender to mutuality, density, and centrality metrics.

What are needed next steps? As a profession, we do devote considerable time and energy to training and development issues (e.g., issuing guidelines for degree programs, providing continuing education opportunities, arranging mentoring sessions at conferences), but we are not adequately studying our pipeline and whether the leaks along the way are problematic or healthy selection and self-selection (regardless of any relationships to gender). Further, although there is a large body of research on women's advancement to draw from, outside of some advice pieces in The Industrial-Organizational Psychologist (TIP) or conference sessions, we know little about the career stories of women in practice in our field and if any of the barriers discussed in that broader literature apply to their advancement. We also need to devote resources to better track the experiences of those seeking a career in our field (applicants to graduate programs, graduate students). The pieces of the picture that are missing on the academic side in terms of representation in other types of programs (MA, PsyD, business schools) can be filled in with just a small amount of effort; the missing information in terms of advancement in practice and in terms of pipeline will require much more effort and resources to obtain.

\section{Recognition}

Indicators of success and prestige, such as fellow status, awards, editorial board membership, and elected office positions can signal what kinds of contributions the field rewards. For example, the percentage of women achieving 
fellow status has been examined for underrepresentation in many disciplines (e.g., $37 \%$ of recognized fellows in the Australian psychiatric workforce are female, Golding, 2015; 18\% of National Academy of Science members are women, Sheltzer \& Smith, 2014). Within the field of psychology as a whole, APA's Center for Workforce Statistics indicates that 32.6\% of APA members in 2015 were fellows, indicating that this is viewed as an honorific in our field.

Further, previous research has identified a potential gap between the number of male and female award winners in a number of disciplines (e.g., men were found to be eight times more likely than women to win a scholarly award in STEM; Lincoln, Pincus, Koster, \& Leboy, 2012; men are more likely to win Young Investigator Awards, Cooper \& Radonjic, 2016). Men and women may differ in the types of awards received. For example, Golbeck and Molgaard (2013) found that women were more likely to receive awards associated within service and teaching rather than awards linked to scholarship. Lincoln et al. (2012) identified a similar trend, finding that women were awarded $10 \%$ of scholarly awards, $32.2 \%$ of service awards, and $37.1 \%$ of teaching awards.

Editorial board membership has often been examined in the literature as a form of recognition, with many fields noting female underrepresentation on boards (e.g., in mathematical sciences, Topaz \& Sen, 2016; management, Metz \& Harzing, 2009; political science, Stegmaier, Palmer, \& van Assendelft, 2011). Finally, leadership in professional societies might also be considered a form of recognition for accomplishments.

How are we doing? To examine recognition via awarded fellowship, we obtained the complete list of Fellows from SIOP's website $(N=357)$ and coded for some of the factors that might influence awarding of fellowship. Specifically, we coded for each Fellow's gender, citation count, H-index, year of PhD graduation, year of Fellow status achievement, and whether the Fellow worked primarily in an academic or applied setting. To obtain each citation count and $\mathrm{H}$-index, we used the Web of Science database. If we could not obtain reliable data for an author through this method (i.e., results included information for additional authors beyond the intended author), we instead obtained the citation count and $\mathrm{H}$-index through the Scopus database $(N=55)$. For analyses involving year of $\mathrm{PhD}$ graduation, 24 Fellows were not included, as this information could not be obtained. Further, analyses involving year of Fellow status achievement excluded 10 Fellows whose information could not be located. As the Fellows whose $\mathrm{PhD}$ years were missing were unique from the individuals missing year of Fellow status, analyses involving both year of $\mathrm{PhD}$ graduation and year of Fellow status achievement omitted 34 Fellows.

We found that of the 357 Fellows, 249 (69.7\%) are male and 108 (30.3\%) are female. We next looked to our samples' citation counts and H-indices 
to see whether there were differences in productivity between male and female Fellows. Specifically, we were interested if potential differences in these metrics could speak to whether certain genders are held to lower or higher standards prior to obtaining Fellow status. We recognized that these indicators of productivity are more relevant for academic than applied Fellows, so we conducted our analyses such that gender differences were examined within each work context. We conducted a one-way MANOVA to examine potential differences in citation counts and $\mathrm{H}$-indices by gender, controlling for year of Fellow $\mathrm{PhD}$ graduation. Within our academically oriented sample, we found no significant differences in citation counts $[F(1,271)=1.64, M S E$ $=9304448.58, p=.201]$ or $\mathrm{h}$-indices $[F(1,271)=1.05, M S E=164.79, p=$ .308] between male and female Fellows. Further, no significant differences were found between male and female applied-oriented Fellows in either citations counts $[F(1,56)=.01, M S E=979084.22, p=.91]$ or h-indices $[F(1$, $56)=.03, M S E=63.71, p=.875]$.

Additionally, we were interested in examining the potential differences between men and women in the number of years it took to become a Fellow after receiving one's $\mathrm{PhD}$. We found no significant differences $[F(1,321)=$ $.04, M S E=61.20, p=.851]$ between male and female Fellows on this metric; specifically, it took on average 18.20 years $(S D=7.81)$ for both men and women to become SIOP Fellows after PhD completion. Finally, we examined whether there were any differences in when the Fellows achieved their status by Fellow gender, ultimately finding that female Fellows tended to receive status more recently $(M=2007.61, S D=8.19)$ than male Fellows $(M=$ $2002.15, S D=12.36), F(1,345)=17.43, M S E=126.44, p<.001$. Specifically, of the Fellows within this sample, the earliest female to achieve such status did so in 1982, in comparison to 1964 for the earliest male Fellow.

The complete list of SIOP award winners was obtained from SIOP's website, from which we recorded the year of each award and the gender of each award winner. The awards ranged from prominent recognitions such as Distinguished Contributions Awards to small grants and graduate student scholarships. Of the 805 awards given by SIOP between 1970 and 2016, 487 $(60.5 \%)$ were received by men and 318 (39.5\%) were received by women. Female winners were more likely to have received awards more recently $(M=$ $2006.42, S D=8.09)$ than male award winners $(M=2005.14, S D=9.35), F(1$, $803)=4.00, M S E=78.74, p=.046$. Such a finding could potentially reflect the increasing representation of women in the field over the course of history or alternatively speak to increased efforts to improve gender representation in award winners within recent years. We additionally examined representation of men and women among some of the most prestigious awards presented by SIOP. Specifically, we looked at the subset of award winners who have received the Distinguished Professional Contributions Award, 
Distinguished Scientific Contributions Award, Distinguished Service Contributions Award, Distinguished Early Career Contributions Award (Practice and Science), and the Distinguished Teaching Contributions Award. Of the 153 award winners recognized in these areas from 1977 to 2016, 124 (81.0\%) were male and $29(19.0 \%)$ were female. Of the science-oriented Distinguished awards (Distinguished Scientific Contributions Award and Distinguished Early Career Contributions Award-Science), only 2 (4.3\%) of the 46 winners were female. Women appear to be more highly represented among Distinguished Teaching Award (46.0\%) and Distinguished Service Contributions Award winners (34.4\%).

Over the years, SIOP has changed the configuration of which positions are elected officers and which positions are appointed committee heads, making it difficult to evaluate data on offices held over time. However, one can look at the key leadership position of president. Of the 72 SIOP presidents, 10 were female, with 9 of these since 1999; the president-elect is also a woman.

Editorships are also key leadership positions within a field, and we looked at JAP and Personnel Psychology as the highest ranked journals most closely associated with I-O psychology. Koppes (2007) indicated that all the editors of JAP from 1917 to 2008 were male, a tradition that has continued in the ensuing years as well (up to 2017). In terms of the current associate editors of the journal, there are equal numbers of men and women. Among the 253 contributing editors (i.e., board members), there are more men than women (66.8\% compared to 33.2\%). For Personnel Psychology, the current editor is female, while the associate editors are majority male (three men to one woman). Similarly to JAP, Personnel Psychology's editorial board features more men than women ( $65.4 \%$ male).

What do we need to explore? There are obviously many other ways members in the field are recognized, there are other leadership positions, and there are other journals whose boards could be examined, so our snapshot here is hardly a complete picture. In particular, practitioners in our field may be more likely to be recognized by external professional organizations as well as organization-specific awards and accolades. Although SIOP certainly publicizes the accomplishments of members, there is no central ability to track recognition in all its forms. Note that our analyses here are limited, as they focus simply on describing outcome rates and do not address deservingness (i.e., factors that might contribute to a particular recognition).

What are needed next steps? As individuals we can all work to make sure that the accomplishments of others (regardless of gender) are recognized by taking time out of our busy lives to nominate them, write in support of nominations, and serve on committees that have the task of making recognition decisions. We need to remain vigilant as to the adequacy of criteria for 
making these decisions. As outlined by the shifting standards model (Biernat \& Fuegen, 2001; Biernat \& Vescio, 2002), it is possible that men and women are judged relative to the expectations associated with their gender rather than on equivalent criteria; this possibility should be considered in the case of recognition within our field and addressed appropriately. Further, as a field we may consider tracking metrics relevant to these recognition decisions; that is, breakdowns of who is being nominated, who has been nominated on multiple occasions, and rates of acceptance/rejection, as such information could indicate whether any concerns are warranted.

\section{Publications and Presentations}

A look at scholarly authorship can potentially speak to gender representation within a given field. Although much literature has reported a historical increase in female authorship across fields (Jagsi et al., 2006), women still comprise the minority of published authors (Jagsi et al., 2006; West, Jacquet, King, Correll, \& Bergstrom, 2013; Knobloch-Westerwick \& Glynn, 2013; Maliniak, Powers, \& Walter, 2013; McDowell, Singell \& Stater, 2006). Such patterns hold even after controlling for a number of relevant factors, including year of publication, venue of publication, theoretical perspective, methodology, tenure status, and institutional affiliation (Maliniak et al., 2013). In a relevant study examining the JSTOR database, KnoblochWesterwick and Glynn (2013) found that women comprised 27.2\% of article authors, men were more likely to hold coveted first and last authorship positions, and women were less likely to write solo-authored papers. Zeng et al. (2016) found that, across six STEM disciplines, women had fewer distinct coauthors and a lower probability of repeating collaborations.

In terms of presentations, researchers in a number of disciplines have considered whether women present as often and, when they do present, whether they are more likely to be first authors on the less prestigious poster presentation and less likely to be part of an invited panel or symposium (e.g., in physical anthropology Isbell, et al., 2012; mammology, Genoways \& Freeman, 2001). There has recently been popular press attention regarding whether women are invited to speak as experts on a variety of topics (Evans, 2016). Indeed, the website http://allmalepanels.tumblr.com documents events, symposia, and more in a wide variety of fields where the panels of experts are only male (Brown, 2017).

How are we doing? Using Journal of Applied Psychology's website, we coded author gender for all articles published in the last five volumes of the journal. Note that this does not necessarily mean that the authors are I-O psychologists, as individuals from many fields can and do publish in our top outlets. This resulted in gender information for 1,612 authors of 458 articles. Additionally, we coded each individual's order of authorship for that article, 


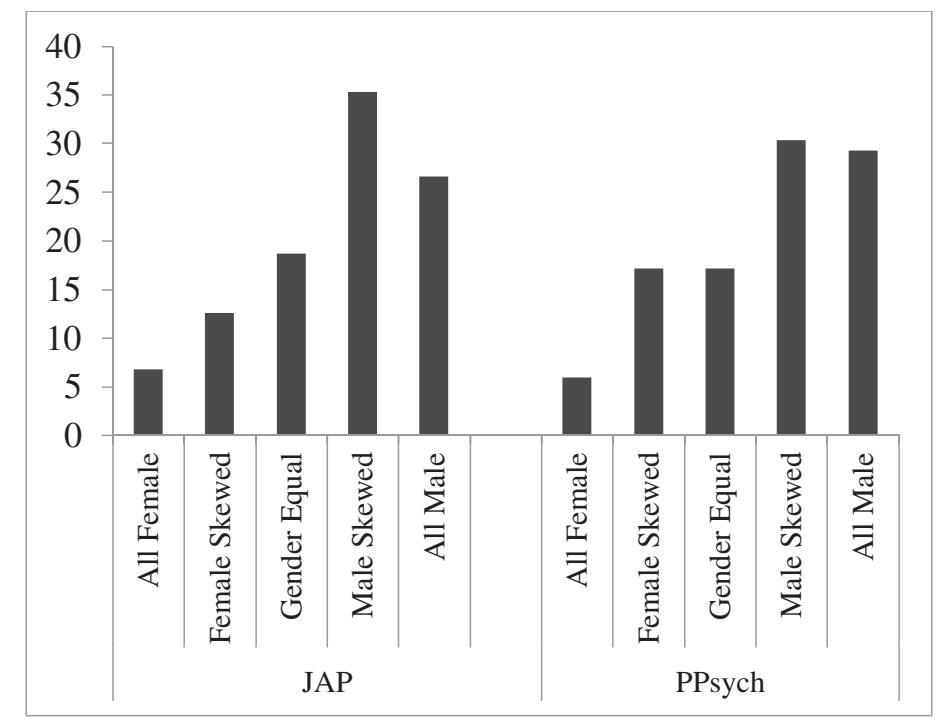

Figure 1. Percentages of gender group composition types for author groups of 2012-2016 Journal of Applied Psychology and Personnel Psychology articles.

as well as the number of authors who wrote each article. This allowed us to examine the gender breakdown among all authors, the gender breakdown among first authors, and whether or not differences exist between men and women on authorship order. Moreover, we examined gender composition of authors within articles. Specifically, we coded each article using a fivepoint scale based on Kanter's (1977) numerical proportions model of gender composition within a group $(1=$ all female, $2=$ female skewed, $3=$ gender equal, $4=$ male skewed, $5=$ all male).

Of the 1,612 authors, 1,054 (65.4\%) were men and 558 (34.6\%) were women. We found a similar pattern when examining the gender breakdown of first authors, as 266 (65.3\%) were men and 159 (34.7\%) were women. We next examined whether order of authorship differed as a function of author gender, ultimately finding no differences between men and women on author order, $F(1,1610)=.04, p=.834$. We additionally explored whether men or women tended to author articles with more or fewer coauthors, again finding no differences on this metric, $F(1,1610)=.45, p=.502$. Finally, we examined gender composition among authors grouped within articles. As seen in Figure 1, the gender composition of author groups tended to be skewed toward being male dominated. Specifically, the "male skewed" category, representing articles written by a group of authors containing more men than women, was the most frequently coded category, with the "all male" category being the second most represented category. Articles written solely by female authors (the "all female" category) was the most infrequently coded 
grouping, representing only 31 of the 458 articles. However, the composition of groups is not surprising given the gender base rates for publication.

To examine whether these patterns were journal specific, we also coded author gender, order, and author group composition for articles published in Personnel Psychology between 2012 and 2016. This resulted in information for 413 authors of 116 articles. We found that the proportion of male and female Personnel Psychology authors (63.2\% male, 36.8\% female) was similar to that of JAP. Further, in testing whether men or women tended to author articles with more or fewer coauthors, we again found no significant differences, $F(1,411)=0.87, p=.352$, as was the case for JAP. However, in contrast to JAP, we found evidence of differences in author order as a function of author gender; specifically, results showed that male authors of Personnel Psychology articles tended to hold earlier authorship positions $(M=2.79, S D$ $=2.44)$ than female authors $(M=3.41, S D=4.08), F(1,411)=3.77, M S E=$ $9.88, p=.053$. Finally, in examining the gender composition among authors grouped within Personnel Psychology articles, we found a pattern similar to that identified in our JAP analyses. As seen in Figure 1, we again found that the gender composition of author groups tended to be skewed toward being male dominated, with the "all-male" and "male-skewed" groups representing the majority of articles.

Using the conference's electronic program available on SIOP's website, we coded authorship and presentation information for all posters, symposia, and panels for the 2016 conference. For the posters, we coded each author's order and gender, as well as the gender breakdown of the authorship groups again using a five-point scale based on Kanter's (1977) numerical proportions model of gender composition within a group $(1=$ all female, $2=$ female skewed, $3=$ gender equal, $4=$ male skewed, $5=$ all male). For the symposia, we coded each participative member's role (chair/co-chair, presenter, discussant) and gender, as well as the gender composition of the group itself. We did not code information for coauthors of presented works, instead only focusing on presenters' information. For panels, we coded each member's role and gender, and again coded for the group's gender composition.

Of the 1,777 authors of presented posters, $943(53.1 \%)$ were men and $834(46.9 \%)$ were women. Of first authors, 304 (53.0\%) were women and 270 $(47.0 \%)$ were men, and there was a pattern of relatively equal representation of composition types, with the "gender equal" comprising the slight majority of posters, as seen in Table 2 . We found no significant differences between men and women in authorship order $[F(1,1775)=0.18, p=.837]$ or number of coauthors, $F(1,1775)=.84, p=.432$.

We coded presenter role, presenter gender, and gender composition of presentation groups for the 115 symposia held at the 2016 SIOP conference. Of all 728 individuals involved in symposia, 355 (48.7\%) were women and 
Table 2. Percentages of Gender Group Composition Types for Each Presentation Form at the SIOP 2016 Annual Conference

\begin{tabular}{lccccc}
\hline \hline & All female & Female-skewed & Equal & Male-skewed & All male \\
\hline Posters & 18.5 & 15.9 & 22.6 & 21.6 & 21.4 \\
Symposia & 4.3 & 32.2 & 14.8 & 43.5 & 5.2 \\
Panels & 1.7 & 31.7 & 12.5 & 32.5 & 5.8 \\
\hline \hline
\end{tabular}

$373(51.2 \%)$ were men. Of those in a chair/co-chair role, 96 (51.6\%) were women and 90 (48.4\%) were men. Of those in a presenting role, $239(49.7 \%)$ were women and $242(50.3 \%)$ were men. Finally, of those in a discussant role, $20(32.8 \%)$ were women and $41(67.2 \%)$ were men. Table 2 displays the frequency of gender composition types within symposia groups, with "female skewed" and "male skewed" as the most frequent compositional make-ups.

In line with our coding of symposia, we coded panelist role, panelist gender, and gender composition of the 101 panels at the 2016 SIOP conference. First looking at the gender breakdown of all individuals involved in a panel, we find that $287(48.2 \%)$ are women and 308 (51.8\%) are men. Of those in a chair/co-chair role, $78(55.3 \%)$ were women and $63(44.7 \%)$ were men. Of those in a panelist role, 209 were women (46.0\%) and 245 (54.0\%) were men. In a similar pattern to the symposia data, Table 2 shows that the "female skewed" and "male skewed" gender composition types were the most frequent among SIOP panels.

What do we need to explore? Studies looking at gender differences in publication patterns go beyond our cursory look here and examine (and often find) differences in journal quality, publication rates over the course of a career, levels of coauthorship and collaboration, and distribution across specialized subfields (e.g., Mihaljevic-Brandt et al., 2016). These studies point to questions we can address within our field: Do women publish at equivalent rates in higher and lower impact outlets? Do women publish at similar rates to men early in their careers (i.e., have different publication records at the time of applying for first job, at time of tenure)? Are there gender differences in subfields or research topics of publications? Although research seems to suggest that men and women are cited by others at equal rates, research has also consistently shown gender differences in self-citation rates, with male authors more likely to self-cite (Descharcht \& Maes, 2017; King, Correll, Jacquet, Bergstrom, \& West, n.d.; Malinak, et al., 2013). A recent examination of citations in I-O psychology textbooks by Aguinis et al. (2017) found that only $17 \%$ of the most cited authors were female. One also could look at the factors that lead to greater work outcomes of an academic nature. For example, in a study of economists, Harter, Becker, and Watts (2011) found 
that male professors, especially those at early career stages, spent less time on teaching and more time on research than women. One area we did not examine is funding. In other fields, there have been some inconsistent findings regarding whether the distribution of grants is equitable across gender groups (see for example Pohlhaus, Jiang, Wagner, Schaffer, \& Pinn, 2011; van der Lee \& Ellemers, 2015).

What are needed next steps? While more detailed analyses of any gender gaps in publication rates may provide useful insights, greater focus on uncovering causal influences is needed, and, should any of those influences represent a bias or barrier, work to remove them should be a concerted professional effort. Because gender differences in outcomes such as publications can be a contributor to any gender differences in pay and recognition outcomes (at least for those in academia), understanding the magnitude and causes of any gender gaps in publications may be important to understanding any differences in those outcomes as well. The field might also questionas researchers have done in enhancing our definitions of performance and considering the relationship between weighting of criteria and adverse impact (Campbell \& Wiernek, 2015; Hattrup \& Roberts, 2010)—whether our criterion space is defined too narrowly (i.e., publication rate as one quantifiable indicator of task performance) in ways that undervalue certain types of contributions (e.g., to practice, to training).

\section{Limitations}

The present study has several limitations that should be noted. First, our analysis is US-centric, and gender representation and equity issues among IO psychologists in other locations may present very different pictures. Second, the data examined were often restricted to a subsample (e.g., faculty from only a subset of I-O PhD programs, authors from one journal) and therefore present only a limited view of the field. Third, the data described here alternate between historical (e.g., awards) and current (e.g., faculty rank, board membership) snapshots of gender representation in the field. A final limitation that needs strong emphasis is that the data collected here tend to speak more to those working in academic than applied areas of I-O psychology. Despite these limitations, the data discussed here can initiate further investigation on a larger scale.

\section{Conclusion}

The purpose of the current article was to (a) briefly review relevant background information regarding gender representation in our field, (b) collect and analyze archival data speaking to representation within our field, and (c) initiate conversation and suggest next steps appropriate to achieving equity in representation across various metrics. Having noted the clear limitations 
of our analyses throughout this article, especially the inability to make any statements regarding causes of differences, we still suggest that the information gathered here may guide us toward key action items in addressing gender representation and equity within our field. In the aggregate, our analysis does put forth a mixed picture, signaling gender equity in many areas and signaling potential concerns in others.

Equitable access and representation across all demographic groups within our profession is likely something to be widely agreed upon as an important value, but without actually gathering information, discussing it, and taking actions, the profession as a whole falls into the category of "not walking the talk." We have provided a number of suggested areas where our collective resources via our professional organization might be directed to do this gathering, monitoring, and changing. However, there are clear limits to what a professional society can do to influence the salary, advancement, training, and work outcomes of those in our field, who pursue their graduate training and careers in many different organizational contexts. Individual members of the field must commit to working toward gender equity within their own spheres of influence. We hope this piece provides a nudge to readers to do so.

\section{References}

Aguinis, H., Ramani, R. S., Campbell, P. K., Bernal-Turnes, P., Drewry, J. M., \& Edgerton, B. T. (2017). Most frequently cited sources, articles, and authors in industrial-organizational psychology textbooks: Implications for the science-practice divide, scholarly impact, and the future of the field. Industrial and Organizational Psychology: Perspectives on Science and Practice, 10(4), 507-557.

American Psychological Association Center for Workforce Studies. (2015). 2005-13: Demographics of the Psychology Workforce. Washington, DC: American Psychological Association.

Beiler, A. A., Zimmerman, L. M., Doerr, A. J., \& Clark, M. A. (2014). An evaluation of research productivity among IO psychology doctoral programs. The Industrial-Organizational Psychologist, 51(3), 40-52.

Biernat, M., \& Fuegen, K. (2001). Shifting standards and the evaluation of competence: Complexity in gender-based judgment and decision making. Journal of Social Issues, 57(4), 707-724.

Biernat, M., \& Vescio, T. K. (2002). She swings, she hits, she's great, she's benched: Implications of gender-based shifting standards for judgment and behavior. Personality and Social Psychology Bulletin, 28(1), 66-77.

Bono, J. E., Braddy, P. W., Liu, Y., Gilbert, E. K., Fleenor, J. W., Quast, L. N., \& Center, B. A. (2016). Dropped on the way to the top: Gender and managerial derailment. Personnel Psychology, 70(4), 729-768. doi:10.1111/peps.12184

Brass, D. J. (1985). Men's and women's networks: A study of interaction patterns and influence in an organization. Academy of Management Journal, 28(2), 327-343.

Brink, M., \& Benschop, Y. (2014). Gender in academic networking: The role of gatekeepers in professorial recruitment. Journal of Management Studies, 51(3), 460-492.

Brown, M. S. (2017, February 28). Eradicate all-male panels to get more women speaking at tech conferences in 2017. Forbes. Retrieved from https://www.forbes.com/sites/metabrown/2017/02/ 28/eradicate-all-male-panels-and-get-more-women-speaking-at-tech-conferences-in-2017/ 3/\#3e17e7ed61d5 
Burress, J. H., \& Zucca, L. J. (2004). The gender equity gap in top corporate executive positions. MidAmerican Journal of Business, 19(1), 55-62.

Campbell, J. P., \& Wiernik, B. M. (2015). The modeling and assessment of work performance. Annual Review of Organizational Psychology and Organizational Behavior, 2, 47-74.

Catalyst. (2017). Women in the Workforce: United States. http://www.catalyst.org/knowledge/ women-workforce-united-states

Ceci, C. J., Ginther, D. K., Kahn, S., \& Williams, W. M. (2014). Women in academic science: A changing landscape. Psychological Science in the Public Interest, 15(3), 75-141.

Cook, A., \& Glass, C. (2014). Above the glass ceiling: When are women and racial/ethnic minorities promoted to CEO? Strategic Management Journal, 35(7), 1080-1089.

Cooper, E. A., \& Radonjić, A. (2016). Gender representation in the vision sciences: A longitudinal study. Journal of Vision, 16(1), 10.

Council of Canadian Academies. Expert Panel on Women in University Research. (2012). Strengthening Canada's research capacity: The gender dimension. Ottawa, ON: Author.

DeMeuse, K. P. (1987). A historical examination of author sex and research funding in industrial and organizational psychology. American Psychologist, 42, 876-879.

Deschacht, N., \& Maes, B. (2017). Cross-cultural differences in self-promotion: A study of selfcitations in management journals. Journal of Occupational and Organizational Psychology, 90, 77-94.

Economou, J. S. (2014). Gender bias in biomedical research. Surgery, 156(5), 1061-1065. doi: 10.1016/j.surg.2014.07.005

Evans, D. (2016, May 9). Death to the all-male panel. NY Mag. Retrieved from http://nymag.com/ thecut/2016/05/all-male-panels-death-knell.html.

Faccio, M., Marchica, M. T., \& Mura, R. (2016). CEO gender, corporate risk-taking, and the efficiency of capital allocation. Journal of Corporate Finance, 39, 193-209. doi: 10.1016/j.jcorpfin.2016.02.008

Genoways, H. H., \& Freeman, P. W. (2001). Evolution of a scientific meeting: Eighty annual meetings of the American Society of Mammalogists, 1919-2000. Journal of Mammalogy, 82, 582-603.

Geraci, L., Balsis, S., \& Busch, A. J. (2015). Gender and the h index in psychology. Scientometrics, 105(3), 2023-2034. doi: 10.1007/s11192-015-1757-5

Gino, F., Wilmuth, C. A., \& Brooks, A. W. (2015). Compared to men, women view professional advancement as equally attainable, but less desirable. PNAS, 112, 12354-12359.

Golbeck, A. L., \& Molgaard, C. A. (2013). Professional awards in statistics: Chipping away at gender disparities in the USA. Paper presented at the 59th International Statistical Institute World Statistics Congress, Hong Kong, China. Retrieved from http://2013.isiproceedings.org/Files/ CPS201-P6-S.pdf.

Goldin, C., Katz, L. F., \& Kuziemko, I. (2006). The homecoming of American college women: The reversal of the college gender gap. Journal of Economic Perspectives, 20(4), 133-156. doi: $10.1257 / 089533006780387391$

Golding, P. M. (2015). Overcoming the gender gap: Increasing gender diversity, scientific scholarship and social legitimacy of our profession. Australasian Psychiatry, 23(3), 222-225. doi: $10.1177 / 1039856215576418$

Harter, C. L., Becker, W. E., \& Watts, M. (2011). Time allocations and reward structures for US academic economists from 1995-2005: Evidence from three national surveys. International Review of Economics Education, 10(2), 6-27.

Hattrup, K., \& Roberts, B. G. (2010). What are the criteria for adverse impact? In J. L. Outtz (Ed.), Adverse impact: Implications for organizational staffing and high stakes selection; adverse impact: Implications for organizational staffing and high stakes selection (pp. 161-197, Chapter xxxv). New York, NY: Routledge/Taylor \& Francis Group.

Hogue, M., DuBois, C. L. Z., \& Fox-Cardamone, L. (2010). Gender differences in pay expectations: The roles of job intention and self-view. Psychology of Women Quarterly, 34(2), 215-227.

Ibarra, H. (1992). Homophily and differential returns: Sex differences in network structure and access in an advertising firm. Administrative Science Quarterly, 37(3), 422-447. 
Isbell, L. A., Young, T. P., \& Harcourt, A. H. (2012). Stag parties linger: Continued gender bias in a female-rich scientific discipline. PLOS ONE, 7, e49682.

Jackson, L. A., Gardner, P. D., \& Sullivan, L. A. (1992). Explaining gender differences in self-pay expectations: Social comparison standards and perceptions of fair pay. Journal of Applied Psychology, 77(5), 651-663.

Jagsi, R., Guancial, E. A., Worobey, C. C., Henault, L. E., Chang, Y., Starr, R., \& Hylek, E. M. (2006). The "gender gap" in authorship of academic medical literature-a 35-year perspective. New England Journal of Medicine, 355(3), 281-287. doi:10.1056/NEJMsa053910

Judge, T. A., Kammeyer-Mueller, J., \& Bretz, R. D. (2004). A longitudinal model of sponsorship and career success: a study of industrial-organizational psychologists. Personnel Psychology, 57, 271303.

Kanter, R. M. (1977). Some effects of proportions on group life: Skewed sex ratios and responses to token women. American Journal of Sociology, 82, 965-990.

King, M. M., Correll, S. J., Jacquet, J., Bergstrom, C. T., \& West, J. D. ( n.d.). Men set their own cites high: Gender and self-citation across fields and over time. Unpublished manuscript. Retrieved from http://www.eigenfactor.org/gender/self-citation/SelfCitation.pdf

Knobloch-Westerwick, S., \& Glynn, C. J. (2013). The Matilda effect-role congruity effects on scholarly communication: A citation analysis of Communication Research and Journal of Communication articles. Communication Research, 40(1), 3-26. doi: 10.1177/0093650211418339

Konrad, A. M., \& Cannings, K. (1997). The effects of gender role congruence and statistical discrimination on managerial advancement. Human Relations, 50(10), 1305-1328.

Koppes, L. L. (1997). American female pioneers of industrial and organizational psychology during the early years. Journal of Applied Psychology, 82, 500-515.

Lee, Y., \& Won, D. (2014). Trailblazing women in academia: Representation of women in senior faculty and the gender gap in junior faculty's salaries in higher educational institutions. Social Science Journal, 51(3), 331-340.

Leibbrandt, A., \& List, J. A. (2015). Do women avoid salary negotiations? Evidence from a large-scale natural field experiment. Management Science, 61(9), 2016-2024.

Lincoln, A. E., Pincus, S., Koster, J. B., \& Leboy, P. S. (2012). The Matilda Effect in science: Awards and prizes in the US, 1990s and 2000s. Social Studies of Science, 42(2), 307-320. doi: $10 / 1177 / 0306312711435830$

Litzky, B., \& Greenhaus, J. (2007). The relationship between gender and aspirations to senior management. Career Development International, 12(7), 637-659.

Lutter, M. (2015). Do women suffer from network closure? The moderating effect of social capital on gender inequality in a project-based labor market, 1929 to 2010. American Sociological Review, 80(2), 329-358.

Lyness, K. S., \& Thompson, D. E. (2000). Climbing the corporate ladder: Do female and male executives follow the same route? Journal of Applied Psychology, 85(1), 86-101.

Magnusson, C. (2009). Gender, occupational prestige, and wages: A test of devaluation theory. European Sociological Review, 25, 87-101.

Maliniak, D., Powers, R., \& Walter, B. F. (2013). The gender citation gap in international relations. International Organization, 67(4), 889-922. doi:10.1017/S00208

McDowell, J. M., Singell, L. D. \& Stater, M. (2006). Two to tango? Gender differences in the decisions to publish and coauthor. Economic Inquiry, 44, 153-168.

McDowell, J. M., Singell, L. D. \& Ziliak, J. P. (2001). Gender and promotion in the economics profession. Industrial and Labor Relations Review, 54, 224-244.

Merluzzi, J., \& Sterling, A. (2017). Lasting effects? Referrals and career mobility of demographic groups in organizations. ILR Review, 70(1), 105-131.

Metz, I. \& Harzing, W. W. (2009). Gender diversity in editorial boards of management journals. Academy of Management Learning \& Education, 8, 540-557.

Mihaljevic-Brandt, H., Santamaria, L., Tullney, M. (2016). The effect of gender in the publication patterns in mathematics. PLoS ONE, 11(10):e0165367. doi:10.1371/journal.pone.0165367. 
Milkman, K. L., Akinola, M. \& Chugh, D. (2015). What happens before? A field experiment exploring how pay and representation differentially shape bias on the pathway into organizations. Journal of Applied Psychology, 100(6), 1678-1712. doi:https://doi.org/10.1037/apl0000022

Morrison, A. M., \& von Glinow, M. A. (1990). Women and minorities in management. American Psychologist, 45(2), 200-208.

Ones, D. S., \& Viswesvaran, C. (2000). Most published authors in Journal of Applied Psychology and Personnel Psychology during the 1990s. The Industrial-Organizational Psychologist, 37, 26-32.

O'Neill, O. A., \& O’Reilly, C. A. (2010). Careers as tournaments: The impact of sex and gendered organizational culture preferences on MBAs' income attainment. Journal of Organizational Behavior, 31(6), 856-876.

Parker, M., \& Welch, E. W. (2013). Professional networks, science ability, and gender determinants of three types of leadership in academic science and engineering. Leadership Quarterly, 24(2), 332-348.

Pohlhaus, J. R., Jiang, H., Wagner, R. M., Schaffer, W. T., \& Pinn, V. W. (2011). Sex differences in application, success, and funding rates for NIH extramural programs. Academic Medicine 86: 759767.

Russo, G., \& Hassink, W. (2012). Multiple glass ceilings. Industrial Relations: A Journal of Economy \& Society, 51(4), 892-915.

Sheltzer, J. M., \& Smith, J.C. (2014). Elite male faculty in the life sciences employ fewer women. Proceedings of the National Academy of Sciences, 111(28), 10107-10112. doi:10.1073/pnas.1403334111

Stegmaier, M., Palmer, B., \& van Assendelft, L. (2011). Getting on the board: the presence of women in political science journal editorial positions. Political Science and Policy, 44: 799-804.

Tharenou, P. (1999). Is there a link between family structures and women's and men's managerial career advancement? Journal of Organizational Behavior, 20(6), 837-863.

Topaz, C. M. \& Sen, S. (2016). Gender representation on journal editorial boards in the mathematical sciences. PLOS ONE, 11: e0161357.

United States Bureau of Labor Statistics. (November, 2015). Highlights of women's earnings in 2014. Downloaded October 29, 2015 from http://www.bls.gov/opub/reports/womensearnings/ archive/highlights-of-womens-earnings-in-2014.pdf

Valla, J. M. \& Ceci, S. J. (2014). Breadth-based models of women's underrepresentation in STEM fields: An integrative commentary on Schmidt (2011) and Nye et al., (2012). Perspectives on Psychological Science, 9, 219-224.

Van der Lee, R. \& Ellemers, N. (2015). Gender contributes to personal research funding success in The Netherlands. PNAS, 112, 12349-12353.

Way, S. F., Larremore, D. B., \& Clauset, A. (2016, April). Gender, productivity, and prestige in computer science faculty hiring networks. In Proceedings of the 25th International Conference on World Wide Web (pp. 1169-1179). Montreal, QC: International World Wide Web Conferences Steering Committee.

West, J. D., Jacquet, J., King, M. M., Correll, S. J., \& Bergstrom, C. T. (2013). The role of gender in scholarly authorship. PLoS ONE, 8(7), e66212. doi:https://doi.org/10.1371/journal.pone.0066212

Zeng, H. T., Duch, J., Sales-Pardo, M., Moreira, J. A. G., Radicchi, F. \& Ribeiro, H. V. (2016). Differences in collaboration patterns across discipline, career stage, and gender. PLoS Biology, 14, e1002573. 